\title{
Increasing Knowledge Flows by Linking Innovation and Health - the Case of SAAVI
}

\author{
REBECCA HANLIN
}

\begin{abstract}
Biotechnology and genomic innovation are seen as increasingly important for achieving public health goals in Africa. In particular, vaccines based on advances in genomic technology are deemed vital in the fight against HIV/AIDS. Public-Private Partnerships (PPPs) provide a collaborative mechanism to ensure these vaccines are developed when the private sector lacks incentives to develop these products. These partnerships provide new mechanisms for transferring the knowledge required to ensure vaccine development occurs as quickly and efficiently as possible. One such vaccine partnership is the South African AIDS Vaccine Initiative (SAAVI). This has been successful in ensuring 'value added' (benefit gained by taking part) is created for those involved particularly in the area of intangible value added determinants of collaboration and knowledge capacity. This paper outlines the results of a case study of SAAVI and argues that it provides evidence of a need to strengthen our understanding of the linkage between wider conceptual 'systems' of innovation and health. In particular, it espouses the usefulness of 'Systems of Innovation' thinking as a means to ensure that more specific focus is placed on process outputs such as collaboration and knowledge capacity. This will ensure that necessary knowledge flow is transferred between those working in the vaccine project for more efficient and effective operations. The research also raises questions about the possibility of such case studies highlighting areas of attention that need addressing if greater linkage is to occur between innovation and health at a wider health research policy level.
\end{abstract}

\section{Genomic technologies, neglected diseases and PPPs}

The 'genomics revolution' has highlighted the potential of new medical technologies. The successful sequencing of the Human Genome has provided the groundwork for the production of applications and technologies that will "revolutionize research in life science and the practice of medicine". The World Health Organisation's 2002 Genomics and World Health report emphasised the role of functional genomics including proteomics, transcriptomics, gene regulation and bioinformatics as creating new solutions to the world's leading health problems such as communicable diseases and cancer.

However, there is growing recognition of a "genomics divide" ${ }^{2}$ whereby developing countries are unable to harness or access the potential benefits of the 'genomics revolution'. In particular it has been shown that $90 \%$ of the world's disease burden receives less than $10 \%$ of global health research spending. ${ }^{3}$ This 10/90 gap has given rise to the term 'neglected diseases' to describe those diseases, particularly affecting developing countries, for which there is little investment to find solutions. Examples of such diseases are HIV/AIDS, TB, malaria, chagas and sleeping sickness. Thus there were only 13 new chemical entities (NCEs) developed related to tropical diseases out of a total of 1223 NCEs developed between 1976 and $1996 .{ }^{4}$ 
One of the reasons put forward to explain why there is so little investment into finding solutions to neglected diseases is an economic one. Certain health related research and development $(R \& D)$ is seen by the private sector - the traditional sector that undertakes R\&D development ${ }^{5}$ - as too risky and expensive to warrant investment. This is particularly true of vaccines for neglected diseases, which although socially important, are deem by industry as unprofitable because the people affected by these diseases lack sufficient purchasing power. One such vaccine is that for HIV/AIDS.

Finding a vaccine for HIV/AIDS is the best long-term solution for a disease that is now the leading cause of death for adults in the world. ${ }^{6} 38$ million people are infected with HIV worldwide, with AIDS claiming three million lives a year. ${ }^{7}$ The economic and social consequences of HIV/AIDS are also dramatic: it is estimated that South Africa's GDP will fall by $17 \%$ by 2010 as a result of AIDS. ${ }^{8}$ These figures have led people to argue that the possible social return on investment in a vaccine will be greater than any investment return to private industry by approximately 10 - to 20 fold. ${ }^{9}$

Growing recognition of the 10/90 gap, the lack of private sector investment and the devastating affect of HIV/AIDS have led to efforts to promote research into vaccines for the disease. In particular, Public Private Partnerships (PPPs) are being seen as innovative collaborative arrangements that provide the right balance of funding and research expertise to develop vaccines for these diseases. ${ }^{10}$ PPPs have been defined as a relationship between at least one private and one public sector player who share (although not necessarily equally) the risk and benefits involved in their activities. ${ }^{11}$ While PPPs provide an economic incentive to collaborate they also provide social incentives to do so because the partners can achieve more together than they can individually, ${ }^{12}$ particularly as the partnership evolves and trust and commitment are strengthened. ${ }^{13}$ PPPs provide an economic incentive to collaborate by reducing economic risks to those involved and a social form of incentive to collaborate by creating a whole greater than the sum of the parts creating "win-win interactions" using mutually beneficial strategies. ${ }^{14}$ As such, PPPs are likely to provide a sustainable mechanism for the development and provision of vaccines for diseases such as HIV/AIDS for the developing world.

Examples of such PPPs include the International AIDS Vaccine Initiative (IAVI), the South African AIDS Vaccine Initiative (SAAVI), the Medicines for Malaria Venture (MMV), the European Developing Countries Clinical Trial Partnership and the Foundation for Innovative New Diagnostics (FIND). These partnerships focus on bringing together public funds to finance product development activities by public and private sector research organisations and others aimed at producing (new) drugs, vaccines and diagnostics. Organisationally these partnerships function, using product development techniques perfected in the private sector, through a not-for-profit organisation that acts as a broker or integrator of knowledge and resources ensuring that these are accessible and delivered to the various partners. ${ }^{15}$ Most of these product development PPPs operate at an international level; however, SAAVI is an example of a product development partnership that is a national level initiative. As such, it is smaller in scale and its partners are more easily defined. 
Using the case study of SAAVI, this paper argues that 'win-win interactions' can be further strengthened within PPPs placed at the intersection of innovation and health if they explicitly, or overtly, acknowledge the importance of the process factors of collaboration and knowledge capacity, as expressed by Systems of Innovation' thinking. This is at odds with the dominant economic argument for the use of PPP mechanisms, which places an emphasis on output. PPPs are seen as the most efficient and effective means to ensure products are developed. In the case of SAAVI, the partnership - as will be explained below - measures its success by the speed and effort spent on working towards developing a successful candidate vaccine against HIV/AIDS.

Systems of Innovation thinking, by contrast, considers the mechanisms by which outcomes are best achieved. In particular, this body of literature places an emphasis on the dynamics of interaction and learning involved in product innovation. Innovation systems approaches developed from the 1970s when questions where asked as to why different countries had different growth rates and whether this was related to research systems, with the concept of 'innovation systems' being coined by Lundvall in 1985. ${ }^{16}$ A system of innovation is "constituted by elements and relationships which interact in the production, diffusion and use of new, and economically useful, knowledge". ${ }^{17}$ This approach is based on the assumption that innovation is a learning process ${ }^{18}$ taking an evolutionary economics perspective to economic growth and technological change which emphasises variety (the processes that influence innovative activity) and selection (the process of choice related to economic importance of different products). ${ }^{19}$ Selection is deemed to take place within the social environment with systemic interaction between actors, ${ }^{20}$ creating a system of innovation that is both social and dynamic. ${ }^{21}$ This interaction is reinforced by - and in turn reinforces - the place of learning within the process of innovation. Thus the two 'tenets' of systems of innovation relate to collaboration and knowledge capacity.

Focusing on the process factors of collaboration and knowledge capacity brings together those involved in vaccine development but who traditionally have worked in separate areas. Acknowledging the role of these process factors would strengthen the vaccine development activities of a PPP such as SAAVI. This paper will also consider the possibility of extending the analysis to the wider area of health research policy. This is because taking process factors of collaboration and knowledge capacity as a starting point suggests the possibility of creating a more sustainable overarching learning system that transcends the traditional barriers between 'innovation' and 'health' at policy level.

\section{The SAAVI case study}

Set up in 2000, SAAVI - a partnership between the South African government, a number of public sector research organisations and private sector and parastatal companies as financiers - aims to develop an effective and affordable HIV vaccine for South Africa and the surrounding region. SAAVI funds clinical development (but not, at the time of this study, clinical trials - although it did assist in the development of infrastructure and start-up activities at clinical trial sites) through a collaborative mechanism centrally coordinated by a directorate and with the expertise of a scientific 
advisory board. SAAVI's research activities are conducted by public research organisations mainly within South Africa.

I conducted a case study of SAAVI in mid-2005. The study considered the extent to which value added, or benefit gained from taking part, had been created for members of the partnership. In particular the case study aimed to investigate whether processrelated intangible benefits such as organisational relations were created, and if they were deemed by partnership members as important for success (defined as 'effective partnership working to ensure a vaccine was developed'). Previous studies on PPPs have focused on larger governance processes and the economic incentives to partnership; there has been little research that considers how process factors played out on the ground within a product development PPP.

In May 2005, semi-structured interviews were conducted with members of the SAAVI directorate, the research groups involved in laboratory studies, clinical trials and ethical or socio-behavioural studies, and major funding agencies. Direct observation and document acquisition were also conducted and the trip had been preceded by a literature review. The data collected covered organisations' partnership activities; why organisations became involved with SAAVI; and partnership progress and future. In particular, interviewees were asked about their organisation's motivations for entering the partnership and the benefits gained from taking part. Interviewees were also asked how partnership success should be measured as a way to understand the importance placed on the benefits gained from taking part.

Figure 1. Typology of value added in the SAAVI partnership

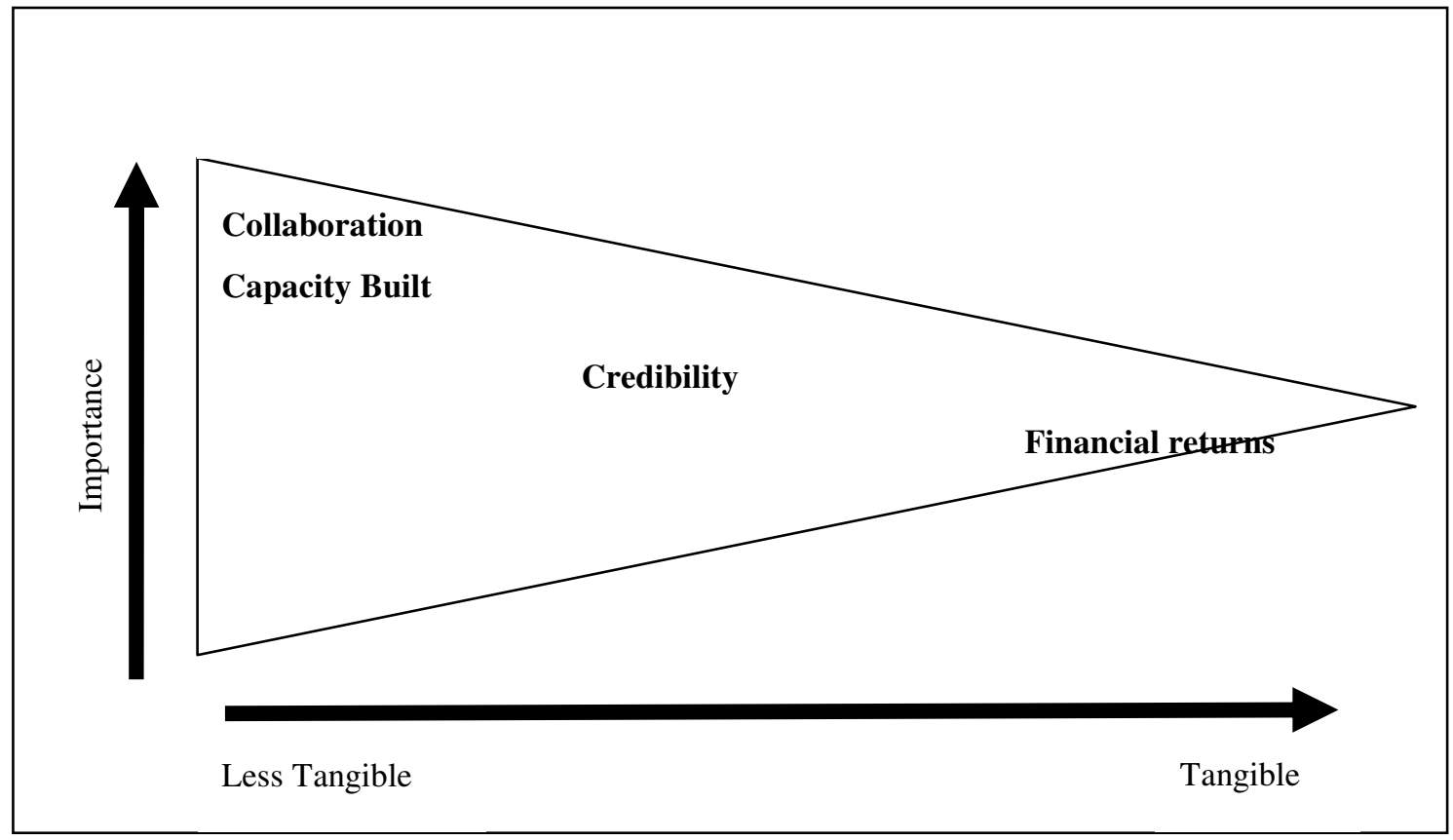

It should be noted that the case study coincided with a period of change within SAAVI. It was in the midst of a management transition and several research grants were about to complete their funding cycle in August 2005. This had led to an 
increase in tension and a major breakdown in communications between the directorate and the research groups as well as an (apparent) lack of coordination from the directorate during this transition. These issues may have influenced how interviewees answered some of the questions.

The data collected showed that those involved in SAAVI had felt value added, or benefit gained from taking part. The benefits gained ranged from tangible financial returns to more intangibly defined benefits relating to collaboration and capacity building. A typology outlining this value added is outlined in Figure 1.

The typology outlines the forms of value added most frequently cited by those interviewed. Collaboration and capacity building were deemed as equally important, less tangible forms of value added by those involved in SAAVI. However, collaboration received a higher importance because it was felt that it was no longer possible to work alone on projects and that such collaboration actually built capacity building opportunities. As interviewees explained:

'Well the global trend with research is if you work on your own is that you get far less done than if you work with others; and you have to leverage as much as possible...And what we were able to do was get far more done than predicted...In addition, the advantage for other researchers was that by collaborating they made themselves more powerful.'

Senior SAAVI directorate leader

and

"with partnership for planning the trials...the immunoassays... making the vaccines... we have managed to build capacity we didn't have before."

Laboratory scientist

Capacity building was therefore a second and subsequent value added for SAAVI members. The term 'capacity building' was used to refer to tangible activities such as staff training and also to more intangible building of knowledge capacity. Interviewees talked about "vast amounts of learning" and having had a "steep learning curve". Although many organisations had been involved in vaccine related work before, few had been involved in HIV vaccine work. Working within the SAAVI partnership meant learning new knowledge not only related to HIV science but also knowledge around community education, HIV prevention, regulation, grant writing and working with others. This occurred at different levels of the partnership: in the laboratories, the clinical sites and within the SAAVI directorate. New knowledge had been gained through partnership activities relating to the process of vaccine production, ethical and legal issues and regulation by those previously uninvolved in such issues:

"We have taken people from straight research through to being able to function in a GLP [Good Laboratory Practice] environment, to understand what is needed to get things through the regulatory council"

Laboratory scientist 
Value added through collaboration and capacity building was seen as a more important form of value added than credibility gained from taking part or financial return. A number of interviewees mentioned that the SAAVI partnership had provided useful sources of funding that would not necessarily have been available from other sectors. Others mentioned that it was sometimes useful "to have that SAAVI name behind you" because SAAVI is a "credit to the world". However comments referring to these two areas of value added were not as numerous as comments relating to collaboration and capacity building.

Despite the high ranking collaboration received as a value added, it was not deemed an important measure of success. The most important measure of success found during data analysis was related to the tangible creation of a vaccine. Successful creation of a vaccine was deemed the most important measure of success and as such the partnership members placed most emphasis on an outcome focus of the partnership over process orientated measures such as capacity building, good structure, communications and work competence. One of the reasons why an emphasis was placed on SAAVI's mission of developing an HIV vaccine - on an outcome focus - is related to the way the partnership was created. Circumstances (the existence of some scientific capacity and the impact HIV/AIDS was having on South Africa) and an altruistic focus (local scientists felt they had the capacity to do something) resulted in SAAVI's creation. The primary focus within SAAVI in its initial years on developing a vaccine had placed a great importance on activities related to the science of vaccinology, particularly preventative vaccines, at the expense of clinical trials and the ethical and socio-behavioural aspects of later-stage vaccine development and bringing a vaccine to market. Overwhelmingly people talked about the fact that "[e]veryone wants to see a vaccine" while "ultimately success will be measured by the degree of achievement of the primary mission of SAAVI". Furthermore, the structure of the SAAVI partnership highlighted this divide by virtue of the fact that the clinical trial sites received less support relative to the work required ${ }^{22}$ while the socio-behavioural research group had only been set up in late 2004.

Thus the measures of success highlighted by interviewees as those the partnership should be measured by were not the same as the factors they identified as being important value added or benefit gained by taking part. This was due to motivation for the partnership being centred on the need to combat the current HIV/AIDS epidemic in South Africa. The result has been an overwhelming focus on production of a product - a viable and effective HIV vaccine. Collaboration between scientists was deemed essential for this to occur but, together with knowledge capacity building, were seen as of secondary importance as a measure of success.

\section{Resonance with Systems of Innovation's focus on collaboration and capacity}

Viewing the partnership through the lens of Systems of Innovation (SI) thinking may provide useful insights on ways forward for a partnership like SAAVI. Work in the area of SI places a strong emphasis on the process factors of collaboration and knowledge-related capacity building, which were the most important value added identified during the SAAVI case study, but were not seen as important measures of success. SI thinking is a holistic approach to innovation that places an emphasis on 
improving the innovation environment to ensure more successful outcomes, suggesting that process factors about how a partnership works can be important success measures.

SI theory was developed - as outlined at the beginning - around the two 'tenets' of collaboration and knowledge capacity. These are seen as a means to improve a firm's ability to innovate. Collaborative arrangements, such as partnerships are seen as a means of managing and extending the knowledge base available. ${ }^{23}$ In particular collaborative arrangements are deemed essential to ensure the full exchange of information. ${ }^{24}$ Greater degrees of collaboration and interaction correlate with higher degrees of learning because competition is lower and there is more trust in the system. ${ }^{25}$

Collaboration assists in the development and transfer of knowledge capacity. The ability of collaboration to transfer knowledge is determined by the extent to which it creates and is further reinforced by "absorptive capacity". Absorptive capacity relates to a firm's ability to recognise the value of knowledge, acquire, assimilate, and apply it. $^{26}$ Absorptive capacity strengthens a firm's ability to implement KM - the ability of a firm to create, codify, transfer and apply knowledge. ${ }^{27}$ Being within a partnership extends the range of knowledge available and increases the resources used in innovation thus improving a firm's absorptive capacity. ${ }^{28}$ Improving absorptive capacity increases the level of learning that occurs and thus further builds absorptive capacity. ${ }^{29}$

The emphasis SI thinking places on collaboration and capacity resonates with the activity of SAAVI and the emphasis SAAVI's members placed on these process factors as important benefits gained from taking part in the partnership. Analysis of the interviews suggests that the SAAVI partnership, through its members' interactions with each other and the outside world, has the ability to create, diffuse and use knowledge to build absorptive or knowledge-based capacity. SAAVI places an implicit emphasis on collaborative activities and knowledge capacity-building activities in its operations while outwardly focusing on progress towards achievement of its objective to develop an HIV vaccine. These activities are seen as an important value added or benefit gained from taking part but as yet are not seen as an important measure of success. SI theory however places these process factors centre stage and imperative for successful innovation:

'economic creativity is actually about the quality of "technological linkages" and "knowledge flows" amongst and between economic agents. Where the interactions are dynamic and progressive great innovative strides are often made. Conversely where systemic components are compartmentalised and isolated from each other, the result is often that relevant bodies are not at all productive. ${ }^{30}$

Focusing more explicitly on the process factors of collaboration and knowledge capacity building suggests a means by which SAAVI could work more effectively towards its goal of developing an HIV vaccine. Emphasising collaboration and making collaborative activities more explicit as a goal provides an opportunity for further knowledge exchange between those involved in vaccine development work. Most obviously it provides greater opportunity for building of stronger scientific 
research capacity through increased skills and knowledge at the level of the laboratory and trial sites. However, the SAAVI partnership brings together these traditional actors in innovation involved in the 'science' or R\&D of possible HIV candidate vaccines with those who are more traditionally involved in healthcare activities and community education activities. As such, an emphasis on collaborative activity and greater knowledge exchange between these groups would also occur. This provides an opportunity to build more understanding and linkages between those working here as community educators and healthcare workers with the scientific staff in the laboratories. This is important as traditional healthcare activities are often viewed as separate from clinical research activities but these are in fact intricately connected. ${ }^{31}$ Partnerships like SAAVI offer a new mechanism for transferring knowledge required to ensure vaccine development occurs as quickly and effectively as possible. Focusing on collaboration and in particular, the knowledge exchange possibilities that this type of partnership can create, provides a means of creating an overarching learning system from which more integrative HIV vaccine development activity within SAAVI would take place.

\section{Discussion - linking innovation and health}

It may be possible to extend this analysis around overarching learning systems in the context of health research policy where there has also been a traditional separation between science and technology innovation and healthcare activities. Science and technology policy has not specifically emphasised health related activities in the past because such policy has been generated from a narrow concept of economic growth. ${ }^{32}$ At the same time, health policy has traditionally only considered healthcare activities. (The World Health Report of 2000 recognised that the concept of health systems in the past concerned the provision and investment in healthcare only.) Thus activities involving science and technology innovation or research have tended not to engage directly with more traditional healthcare related provision activities.

There is growing recognition of the need to consider science and technology innovation and healthcare activities at the same time. There are calls that the science and technology, particularly biotechnology related $R \& D$, capacity of developing countries is important if they are to achieve the Millennium Development Goals ${ }^{33}$ and that these are important inputs to a health system. Emphasis is also being placed on strengthening 'health research' - "the generation of new knowledge using the scientific method to identify and deal with health problems" 34 - in developing countries and the need to close the 10/90 health research gap. Such research refers not only to the generation of scientific knowledge on new products and processes (R\&D) but also knowledge relating to their application and utilisation ${ }^{35}$ so that more informed policy and practice can take place.

Health policy analysts have developed the concept of a 'health research system, ${ }^{36}$ as a conceptual tool around which policy makers in developing countries can work to strengthen health research activities. This system consists of the "people, institutions and activities whose primary purpose is to generate and apply high-quality knowledge that can be used to promote, restore and/or maintain the health status of populations" 37 and lies at the intersection between the health system and the wider research system. 
The idea of a health research system highlights the way those involved in the healthcare system and those conducting traditional research activities can generate useable and relevant health research knowledge. This goes some way towards the idea of creating an overarching learning system but without the emphasis placed on the collaborative activity that such a system requires. A concept related to health research strengthening that does encompass this is that of the 'health innovation system' which has been developed from SI thinking. A health innovation system is the network of institutions whose "interactions and activities generate and/or use scientific knowledge and produce (as well as apply) technologies to solve specific disease problems". ${ }^{38}$

This concept places an emphasis on process factors of collaboration and knowledge capacity at the policy level when considering health research activities. This may provide a means of creating a more sustainable overarching learning system that would transcend the traditional barriers between 'innovation' and 'health' at the policy level and provide a way to reduce the gap between seemingly discrete 'systems' of science and technology innovation and health.

\section{Conclusion}

The SAAVI case study highlights the undervalued nature that the process factors of collaboration and knowledge capacity have been given within the partnership. While seen as important benefits gained from taking part in the SAAVI partnership by members, they were not seen as important measures of success. This is despite the fact that both were deemed important for member's activities within the partnership and, therefore, for the process of the partnership itself. As such, the members within the SAAVI partnership appeared to put an implicit as opposed to an explicit or overt emphasis on these process factors. SI thinking recognises the value of these process factors. It places an emphasis on collaboration and capacity as being central to advancing innovative activities through partnership. Focusing explicitly on these process factors may provide a means of creating an overarching learning system. Within this system it is possible to work towards objectives much more effectively as knowledge flow is increased within a partnership between those working in vaccine development activities in areas of scientific $R \& D$ and those involved in healthcare work.

The case study also raises questions about the possibility of such studies highlighting areas that need addressing if greater linkage is to occur between innovation and health at a health research policy level. The SAAVI case study showed the existence of a linkage between innovation and health. Embracing this linkage within the wider research policy sphere is necessary because scientific capacity is not a means to an end but an important end in itself within the health system. There is a need for the policy system to work within a wider systemic approach that includes not only health but also science and technology. An emphasis on collaboration and absorptive capacity within the health research policy environment would move beyond references to the 'health system,' which is seen simply in terms of outcomes with vaccines as a product input that assists service provision. Such a perspective would instead acknowledge the importance of output (knowledge capacity) for the building of a wider conceptualised systemic framework to health research policy. This does not 
mean championing output process factors such as knowledge or absorptive capacity over outcomes, but instead stresses their inter-relationship. This is because an emphasis is placed on the role of absorptive capacity (understanding the value and use of knowledge) in linking science and technology innovation or research activities with healthcare activities.

It would be wrong - after only one small case study - to advocate the use of either the conceptual frameworks 'health innovation systems' or the 'health research system' as being the way forward in ensuring a more connected health research policy arena. This case study was, at most, an institutional level study but it does suggest that more research needs to be done in this area. This is a young and as yet rather unexplored area of research, and conducting a small case study of SAAVI raises more questions than it answers and opens a number of avenues for further research. For example, it highlights a need to consider what information should be transferred within a vaccine partnership in order to be successful and that there are possible lessons to be learnt for the wider area of health research policy.

Furthermore, the case study has introduced an issue that potentially could have significant impact on the way policy is formulated. More systemic frameworks such as 'health innovation systems' and the 'health research system' are being supported but little work has yet been conducted to consider how such frameworks should be moved forward. This paper highlights the possibility of using institutional level analysis of health research activities that spans the innovation and health divide as one possible way forward. The paper also highlights the potential use of systems of innovation thinking as a framework within which to work.

The aim of this paper has been to highlight that studying activities at an institutional level can provide important insights for the wider policy arena to take into account. The case of HIV/AIDS vaccine development in South Africa provides one example of where an institutional level study of a research partnership highlights the interaction between what are usually - particularly within the wider policy arena - considered as separate areas of activity, namely (science and technology research) innovation and health(care provision). Focusing on the process factors of collaboration and knowledge capacity may provide a means of creating a more sustainable overarching learning system that would reduce the gap between seemingly discrete 'systems' of science and technology innovation and health within the partnership. This paper suggests that focusing on these may also provide a means to move towards not only more integrated vaccine development work, but also to more integrated systemic health research policy.

\section{Acknowledgements}

I would like to thank James Smith, Joanna Chataway and the referees of this paper for their comments. Any mistakes are the author's own.

\footnotetext{
${ }^{1}$ P. Gwynne and G. Heebner () Breakthroughs in life sciences technologies. Science 30 November 2001 (supplement). Available at www.sciencemag.org/products/breakthroughs.dtl (accessed 17/09/06).
} 
${ }^{2}$ E. Dowdeswell, A.S. Daar, and P. Singer. Bridging the Genomics Divide. Global Governance Journal 2003; 9: 1-6.

${ }^{3}$ Global Forum for Health Research. 1999. The 10/90 Report on Health Research. Geneva: Global Forum for Health Research.

${ }^{4}$ D. Webber and M. Kramer. Perspectives on stimulating industrial research and development for neglected infectious diseases. Bulletin of the World Health Organisation 2001; 79(8): 735-41.

${ }^{5}$ P. Trouiller, P. Olliaro, E. Torreele, J. Orbinksi, R. Laing and N. Ford. Drug Development for neglected diseases: a deficient market and public-health policy failure. Lancet 2002; 359: 2188-94. ${ }^{6}$ WHO. 2004. Knowledge for Better Health. Geneva: WHO.

${ }^{7}$ UNAIDS. 2004. 2004 Report on the Global AIDS Epidemic. Geneva: UNAIDS.

${ }^{8}$ UNAIDS. 2003. Accelerating action against AIDS in Africa. Geneva: UNAIDS.

${ }^{9}$ M. Kremer. 2000. Creating Markets for New Vaccines - Part 1: Rationale. Working Paper w7716. Cambridge, Mass: NBER.

${ }^{10}$ J. Chataway and J. Smith. The International AIDS Vaccine Initiative: Is it getting new science and technology to the world's neglected majority? World Development 2006; 34(1): 16-30.

${ }^{11}$ R. Widdus. 2003. Private Sector Action for Health: Public-Private Partnerships. Presentation for the Initiative on Public-Private Partnerships for Health. Available at http://www.ippph.org/ (accessed 30/3/04).

${ }^{12}$ G.J. Bazzoli, R. Stein, J.A. Alexander et al. Public-Private Collaboration in Health and Human Service Delivery: Evidence from Community Partnerships. Millbank Quarterly 1997; 75(4): 533-561.

${ }^{13}$ A. Parkhe. Strategic alliance structuring: a game theoretic and transaction cost examination of interfirm cooperation. Academy of Management Journal 1993; 36(4): 794-829.

${ }^{14}$ A. Batson. Win-win interactions between the public and private sectors. Nature Medicine 1998; 4(3): 487.

${ }^{15}$ J. Chataway et al (2007) The International AIDS Vaccine Initiative (IAVI) in a changing landscape of vaccine development: a public private partnership as knowledge broker and integrator. European Journal of Development Research (in press).

${ }^{16}$ B.A. Lundvall, M. Muchie and P. Gammeltoft. 2003. Introduction. In Putting Africa First: The Making of African Innovation Systems. M. Muchie, P. Gammeltoft and B.A. Lundvall, eds. Aalborg: Aolborg University Press.

${ }^{17}$ B.A. Lundvall. 1995. National Systems of Innovation: towards a theory of innovation and interactive learning. London: Pinter: 2.

${ }^{18}$ G. Dosi. 1988. The Nature of the Innovative Process. In G. Dosi et al, eds. Technical Change and Economic Theory. London: Pinter.

${ }^{19}$ J.S. Metcalfe. Evolutionary Economics and Technology Policy. The Economic Journal 1994; 104 : 931-944.

${ }^{20}$ B. Carlsson and R. Stankiewicz. On the nature, function and composition of technological systems. Journal of Evolutionary Economics 1991; 1: 93-118.

${ }^{21}$ R Narula. 2003. Globalization and Technology. Cambridge: Polity.

${ }^{22}$ Clinical trials themselves are not specifically financially supported through SAAVI nor is parallel but important HIV prevention and palliative care work.

${ }^{23}$ T. Hewitt. 2000. A Hybrid or a Third Way? Contemporary Thinking on Inter-Organisational

Relations. In Managing Development: Understanding Inter-organisational Relationships. D. Robinson, T. Hewitt and J. Harriss, eds. London: Sage and Open University.

${ }^{24}$ B. Carlsson and R. Stankiewicz. On the nature, function and composition of technological systems. Journal of Evolutionary Economics 1991; 1: 93-118.

${ }^{25}$ Lundvall.B.A. and Borras, S. 1998. The Globalising Learning Economy: Implications for Innovation Policy. The European Commission, DG XII-TSER, Bruxelles; see B. Johnson and B.A. Lundvall. 2002. National Systems of Innovation and Economic Development. In Muchie et al, eds, op. cit. note 16.

${ }^{26}$ W.M. Cohen and D.A. Levinthal. Absorptive Capacity: A New Perspective on Learning and Innovation. Administrative Science Quarterly 1990; 35: 128-52.

${ }^{27}$ A. Daghfous. Knowledge Management as an organisational innovation: an absorptive capacity perspective and a case study. International Journal of Innovation and Learning 2004; 1(4): 409-422.

${ }^{28}$ J.T. Scott. 2002 Absorptive Capacity and the Efficiency of Research Partnerships. Working Paper Available at www.dartmouth.edu/ jtscott/Papers/Scott0930TA\&SM.pdf (accessed on 20/06/05).

${ }^{29}$ W.M. Cohen and D.A. Levinthal. Absorptive Capacity: A New Perspective on Learning and Innovation. Administrative Science Quarterly 1990; 35: 128-152. 


\footnotetext{
${ }^{30}$ N. Clark. 2000. Innovation Systems Institutional Change and the New Knowledge Market: Implications for Third World Agricultural Development. Strathclyde Papers in Economics 2000/10, p.12.

${ }^{31}$ M. Elston, ed. 1997. The Sociology of Medical Science and Technology. Oxford \& Maiden, MA: Blackwell.

${ }^{32}$ P Freeman and M. Miller. 2001. Scientific Capacity Building To Improve Population Health: Knowledge as a Global Good. CMH Working Paper WG2:3.

${ }^{33}$ See M. Csazzar and B. Lal. 2004. Improving Health in Developing Countries. Issues in Science and Technology 2004 (Fall issue).

${ }^{34}$ WHO Commission on Health Research for Development. 1990. Health research: essential link to equity in development. Oxford: Oxford University Press: 13.

${ }^{35}$ T. Pang, R. Sadana, S. Hanney, Z.A. Bhutta, A.A. Hyder and J. Simon. Knowledge for better health a conceptual framework and foundation for health research systems. Bulletin of the World Health Programme 2003; 81: 815-820.

${ }^{36}$ Ibid.

${ }^{37}$ WHO. 2000. Health Systems: Improving Performance Geneva: WHO.

${ }^{38}$ Ibid.
} 